\title{
ENTUPIMENTO DE TUBOS GOTEJADORES CONVENCIONAIS COM APLICAÇÃO DE CLORETO DE POTÁSSIO (BRANCO E VERMELHO) VIA DUAS QUALIDADES DE ÁGUA
}

\section{PABBLO A. DE A. RIBEIRO ${ }^{1}$, RUBENS D. COELHO ${ }^{2}$, MARCONI B. TEIXEIRA ${ }^{3}$}

RESUMO: Neste trabalho, buscou-se avaliar a suscetibilidade de modelos de tubos gotejadores ao entupimento, quando expostos ao uso de cloreto de potássio (branco e vermelho), aplicados via diferentes qualidades de água. O experimento foi realizado no Laboratório de Irrigação do Departamento de Engenharia Rural da Escola Superior de Agricultura "Luiz de Queiroz" ESALQ/USP, por um período de nove meses, analisando o desempenho de oito modelos de tubos gotejadores convencionais, com quatro tratamentos e dez repetições, sendo cada repetição representada por um gotejador. Os tratamentos aplicados foram: (T1-Lg/B) água do lago x cloreto de potássio branco; (T2-Lg/V) água do lago x cloreto de potássio vermelho; (T3-Lb/B) água do laboratório x cloreto de potássio branco, e $(\mathrm{T} 4-\mathrm{Lb} / \mathrm{V})$ água do laboratório x cloreto de potássio vermelho. Os modelos de tubos gotejadores apresentaram desempenhos variáveis, sugerindo que a arquitetura interna dos gotejadores foi o fator determinante na caracterização do processo de entupimento. Não foi observado elevado entupimento com relação à aplicação dos cloretos de potássio branco e vermelho na ausência ou presença de fitoplâncton, mostrando que é possível utilizar cloreto de potássio vermelho em fertirrigação.

PALAVRAS-CHAVE: fertirrigação, uniformidade de distribuição, irrigação localizada.

\section{CLOGGING OF CONVENTIONAL DRIPLINES UNDER THE APPLICATION OF POTASSIUM CHLORIDE (WHITE AND RED) WITH TWO WATER QUALITIES}

\begin{abstract}
This work aimed to evaluate the susceptibility of several dripline models against the clogging process when exposed to potassium chloride (white and red), applied through different water qualities (fertigation). The experiment was accomplished in three phases, at the Laboratory of Irrigation of the Department of Rural Engineering at ESALQ/USP, for a period of nine months, by analyzing the performance of eight conventional drip models, with four treatments and ten repetitions, being each repetition a dripper. The applied treatments were: (T1-Lg/B) water of the lake $\mathrm{x}$ chloride of white potassium; (T2-Lg/V) water of the lake $\mathrm{x}$ chloride of red potassium; (T3$\mathrm{Lb} / \mathrm{B})$ water of the laboratory $\mathrm{x}$ chloride of white potassium and $(\mathrm{T} 4-\mathrm{Lb} / \mathrm{V})$ water of the laboratory $\mathrm{x}$ chloride of red potassium. The dripline models presented variable performance, suggesting that internal architecture of emitters is a major factor related to clogging resistance for imposed treatments. It was not observed high clogging with the application of white or red potassium chloride, under different water quality conditions, showing that it is possible to use the red potassium chloride for fertigation without problems.
\end{abstract}

KEYWORDS: fertigation, uniformity of distribution, localized irrigation.

\footnotetext{
${ }^{1}$ Eng ${ }^{\mathrm{o}}$ Agrônomo, Mestre em Agronomia, Departamento de Engenharia de Biossistemas, LEB - ESALQ/USP, Piracicaba - SP, Fone: (0XX19) 3447.8551, pabbloagro@yahoo.com.br

${ }^{2}$ Eng ${ }^{\mathrm{o}}$ Agrônomo, Prof. Livre Docente, Departamento de Engenharia de Biossistemas, LEB - ESALQ/USP, Piracicaba - SP, Fone: (0XX19) 3447.8551,rdcoelho@esalq.usp.br

${ }^{3}$ Eng $^{\mathrm{o}}$ Agrônomo, Prof. Dr., Instituto Federal Goiano, IFGoiano, Câmpus Rio Verde, Rodovia Sul Goiana, km 01, Zona Rural, Rio Verde - GO, Fone: (0XX64) 3620.5600, marconibt@gmail.com

Recebido pelo Conselho Editorial em: 28-8-2008
}

Aprovado pelo Conselho Editorial em: 17-3-2010 


\section{INTRODUÇÃO}

A água é um recurso natural em escassez, em muitas regiões do planeta e do Brasil. Atualmente, um dos sistemas mais apropriados e em notável expansão é o sistema de irrigação por gotejamento, o qual apresenta algumas vantagens, sendo a economia de água e energia as mais citadas na atualidade, frente à situação da disponibilidade de água no planeta. Outra grande vantagem é a possibilidade de automação e fertirrigação, duas práticas que fazem deste sistema o mais eficiente, reduzindo os custos com mão de obra e tornando mais preciso o manejo da água e da nutrição das culturas. Além disso, apresenta baixo risco de contaminação de operadores em campo e do produto agrícola final, o que possibilita o uso de água residuária na produção agrícola (COELHO, 2007).

O entupimento de emissores continua sendo o principal problema em sistemas de irrigação por gotejamento. Para culturas anuais de alto valor econômico e para culturas perenes onde a longevidade do sistema é especialmente importante, emissores entupidos podem ocasionar perdas econômicas. Não há um método quantitativo simples e único para calcular o potencial de entupimento de um determinado sistema de irrigação por gotejamento. A qualidade da água pode mudar ao longo do ano de forma que amostras de água deveriam ser analisadas em diferentes períodos da irrigação (PIZARRO, 1996).

AYERS \& WESTCOT (1991) afirmam que as obstruções causadas pelas precipitações químicas ocorrem gradualmente e, portanto, sendo mais difíceis de serem localizadas. As obstruções por microrganismos (fitoplâncton - algas e zooplâncton - bactérias) que se desenvolvem, alimentando-se de resíduos orgânicos ou inorgânicos presentes nas águas são causadas pelos filamentos dos microrganismos que crescem formando uma matriz gelatinosa e pegajosa, que se adere nas partes internas da tubulação e dos emissores. Já as obstruções oriundas de material em suspensão são as de mais fácil solução, haja vista que um eficiente sistema de filtragem pode reduzir significativamente o problema (CORDEIRO et al., 2003; SOUZA et al., 2006).

A obstrução dos emissores está diretamente relacionada à qualidade da água de irrigação. Portanto, os sólidos em suspensão, a composição química e a atividade microbiológica ditam o tipo de tratamento de água necessário para prevenção das obstruções (COELHO, 2007).

Dada a importância do sistema de irrigação localizada, principalmente com alternativas para o problema de escassez de água, eficiência na prática da fertirrigação e seu crescente mercado nos últimos anos, este trabalho teve por objetivo avaliar a suscetibilidade dos principais gotejadores convencionais do mercado submetidos à aplicação de dois tipos de cloreto de potássio (branco e vermelho) via diferentes qualidades de água; verificando se o uso do cloreto de potássio vermelho, oferece maior potencial ao entupimento e se é recomendado para prática de fertirrigação, assim como a qualidade da água, associada ao uso do cloreto de potássio, pode potencializar a suscetibilidade ao entupimento dos tubos gotejadores avaliados.

\section{MATERIAL E MÉTODOS}

Este experimento foi conduzido no Laboratório de Irrigação do Departamento de Engenharia Rural, da Escola Superior de Agricultura "Luiz de Queiroz" - ESALQ/USP, utilizando-se de bancada de ensaios em estrutura metálica, com $11,0 \mathrm{~m}$ de comprimento por 4,0 $\mathrm{m}$ de largura e 5,80 m de altura, composta por quatro módulos experimentais.

Avaliou-se a suscetibilidade dos tubos gotejadores ao entupimento submetidos à aplicação de cloreto de potássio branco e vermelho (fornecido pela empresa Fertibrás), aplicados via duas qualidades de água: uma proveniente do lago artificial do Departamento de Engenharia Rural da ESALQ/USP, utilizada para o abastecimento dos reservatórios 1 e 2 e água tratada (água do Laboratório), proveniente da estação de tratamento de água da ESALQ/USP - Rio Piracicaba - SP, utilizada para o abastecimento dos reservatórios 3 e 4 . 
A combinação do fator A (tipo de cloreto de potássio) versus o fator B (qualidade de água) resultou nos quatro tratamentos aplicados: (T1-Lg/B) água do lago x cloreto de potássio branco; (T2-Lg/V) água do lago x cloreto de potássio vermelho; (T3-Lb/B) água do laboratório x cloreto de potássio branco, e (T4-Lb/V) água do laboratório x cloreto de potássio vermelho. Para isso, utilizaram-se oito modelos de gotejadores convencionais existentes no mercado nacional, utilizando-se dos mais comercializados, segundo os fabricantes, embora ocorra variação em relação às regiões e às culturas em que o sistema é implantado (Tabela 1).

TABELA 1. Características técnicas dos modelos de tubos gotejadores de acordo com os fabricantes: vazão, diâmetro interno (Di), pressão de serviço (PS) e sistema de funcionamento. Technical characteristics of dripper models according to the manufacturers: flow rate, internal diameter (ID), pressure (PS) and operation system.

\begin{tabular}{|c|c|c|c|c|c|}
\hline Fabricante & Modelo & $\frac{\text { Vazão }}{\mathrm{Lh}^{-1}}$ & $\frac{\mathrm{Di}}{\mathrm{mm}}$ & $\begin{array}{l}\mathrm{PS} \\
\mathrm{kPa}\end{array}$ & $\begin{array}{c}\text { Sistema de } \\
\text { funcionamento }\end{array}$ \\
\hline Netafim & Tiran & 2,2 & 16 & 300 & Convencional \\
\hline Netafim & Super Typhoon & 2 & 16 & $50-200$ & Convencional \\
\hline Plastro & Hydrogol & 2 & 15 & 80 & Convencional \\
\hline Naan & Naan Paz & 1,7 & 17 & $100-300$ & Convencional \\
\hline Naan & Naan Tif PC & 1 & 16 & $100-400$ & Convencional \\
\hline Amanco & Amancodrip PC & 2,3 & 16 & $100-400$ & Convencional \\
\hline Petroísa & Petro drip & 1,5 & 16 & $75-200$ & Convencional \\
\hline Azud & Azud Line & 1,4 & 17 & $100-350$ & Convencional \\
\hline
\end{tabular}

O espaçamento entre emissores, a vazão e as demais características técnicas dos tubos gotejadores foram mantidos conforme a disponibilidade comercial, evitando-se alterar o espaçamento original de cada tubo gotejador. De acordo com RESENDE (1999), a manutenção das características originais de fábrica é apropriada para reduzir erros e representar melhor a condição real do sistema de irrigação no campo.

Em razão da não existência de norma específica para ensaios de entupimento de gotejadores, conforme as normas técnicas (ISO, ASAE e ABNT), os modelos de tubos gotejadores utilizados nos ensaios tiveram seus nomes comerciais codificados como forma de evitar especulações comerciais. Assim, os modelos foram codificados ( $\mathrm{C} 1$ - gotejador convencional modelo $\mathrm{Y})$, de forma aleatória, não apresentando nenhuma relação com o nome dos produtos apresentados na Tabela 1. A identificação parcial dos emissores poderá ser solicitada aos autores, através dos e-mails dos mesmos.

O sistema de pressurização utilizado no experimento foi composto por duas motobombas centrífugas da marca KSB, modelo KSB Hydrobloc C750, sendo cada conjunto motobomba específico para a aplicação de uma determinada qualidade de água (Figura 1A). A operação de funcionamento das bombas, quanto ao horário de início e término de cada ciclo de aplicação, foi realizada manualmente, obedecendo aos horários de início, duração de aplicação e ensaio de vazão. Para evitar a entrada de partículas em suspensão no sistema, com tamanho superior ao diâmetro dos emissores, foi utilizado um filtro de disco de $120 \mathrm{mesh} /$ Amiad (Figura 1B), com capacidade para $15 \mathrm{~m}^{3} \mathrm{~h}^{-1}$ de vazão.

À entrada de cada nível, instalou-se uma tomada de pressão, permitindo o ajuste da pressão de serviço no início de cada tubo gotejador durante os ensaios de vazão, e quando necessário, ajustada àquela preestabelecida. Para a medição e monitoramento da pressão de serviço, foi utilizado um manômetro com faixa de leitura de 0 - $700 \mathrm{kPa}$.

Conduziu-se o experimento durante um período de nove meses, com 936 horas acumuladas de aplicação de cada tratamento. O procedimento de aplicação consistiu em 13 etapas, sendo cada etapa composta de seis ciclos. No manejo de cada ciclo, os tratamentos permaneciam 12 horas em 
aplicação contínua e 36 horas em repouso. Ao final de uma etapa, cada unidade de aplicação ou tratamento acumulou um total de 72 horas de aplicação dos respectivos tratamentos e 216 horas de repouso.
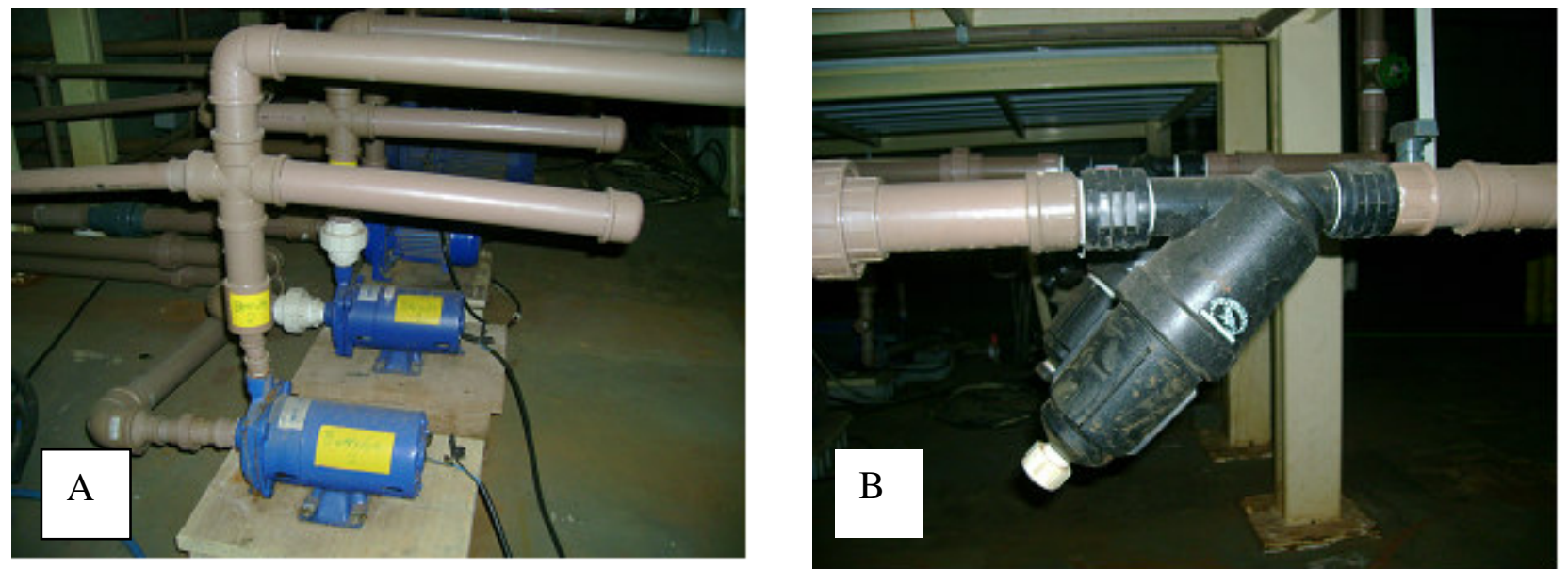

FIGURA 1. Motobombas centrífugas e filtro de disco de $120 \mathrm{mesh} /$ Amiad, utilizado no sistema de irrigação do experimento. Centrifugal pumps and disk filter of $120 \mathrm{mesh} / \mathrm{Amiad}$ used during the irrigation research.

A aplicação das soluções consistiu em um sistema fechado, ou seja, um processo de recirculação da solução. Para isso, foi instalado um sistema de captação da solução gotejada. $\mathrm{O}$ sistema de recolhimento foi composto por dois conjuntos de telhas de aço zincado, colocadas abaixo dos tubos, com inclinação de 3\%, que conduzia a solução gotejada para uma calha de aço zincado, localizada no centro do módulo. A partir dessa calha, a solução retornava para a respectiva caixa de captação, através de um conjunto de tubos PVC de $0,1 \mathrm{~m}$ de diâmetro. Além disso, foram instalados rufos nas margens das telhas, com $0,3 \mathrm{~m}$ de altura e cortinas de plásticos para evitar perdas de solução provocadas pelos respingos, gerados pelo impacto das gotas na superfície da telha.

Em razão da falta de estudos anteriores relacionados a entupimento de gotejadores, provocado pela aplicação de cloreto de potássio, adotou-se como critério para a concentração inicial da solução um nível de salinidade, com condutividade elétrica de $2,5 \mathrm{dS} \mathrm{m}^{-1}$ da solução utilizada nas aplicações. Para determinar essa concentração do produto a ser adicionada na água de irrigação, foi realizado um teste em laboratório, determinando-se a quantidade de produto comercial a ser adicionada no reservatório com $0,8 \mathrm{~m}^{3}$ de água.

O procedimento para a realização da leitura de vazão consistiu na pressurização do sistema, estabilização da pressão em $150 \mathrm{kPa}(+/-5 \mathrm{kPa})$ no início da linha, posicionamento dos coletores sob os respectivos gotejadores, com 3 segundos de defasagem, e retirada dos coletores com a mesma sequência e defasagem de tempo, após 5 minutos de coleta. Para obter-se maior exatidão, foi utilizado o método gravimétrico para a determinação do volume coletado de cada emissor, expressando-se os valores de vazão em $1 \mathrm{~h}^{-1}$. Foi utilizada uma balança de precisão certificada (OHAUS), com precisão de 0,01 g.

Para a comparação dos tratamentos, realizou-se o monitoramento da vazão dos gotejadores $\left(\mathrm{L} \mathrm{h}^{-1}\right)$, do coeficiente de variação de vazão $(\%)$, da uniformidade de distribuição (\%) e do grau de entupimento (\%), calculados pelas eqs.(1), (2), (3) e (4), respectivamente. Vale lembrar que os valores da leitura inicial (leitura de referência) correspondem à vazão inicial ( $q_{\text {inicial }}$ ), coeficiente de variação de fabricação $\left(\mathrm{CV}_{\mathrm{f}}\right)$ e uniformidade de distribuição inicial ( $\left.\mathrm{UD}_{\text {inicial }}\right)$; enquanto os valores das leituras posteriores correspondem à vazão do gotejador usado $\left(\mathrm{q}_{\text {usado }}\right)$, coeficiente de variação de vazão $\left(\mathrm{CV}_{\mathrm{q}}\right)$ e uniformidade de distribuição do gotejador usado ( $\left.\mathrm{UD}_{\text {usado }}\right)$. 


$$
\mathrm{q}=\frac{\mathrm{P}}{1000 \mathrm{t} \gamma} 60
$$

em que,

q - vazão do gotejador, $\mathrm{L} \mathrm{h}^{-1}$

$\mathrm{P}$ - peso da água coletada, $\mathrm{g}$;

$\mathrm{t}$ - tempo de coleta, min, e

$\gamma$ - peso específico da água utilizada no ensaio (o valor médio utilizado para conversão da água para $25^{\circ} \mathrm{C}$, foi de 0,997 ).

$$
\mathrm{CV}_{\mathrm{q}}=\frac{\mathrm{s}}{\overline{\mathrm{q}}} 100
$$

em que,

$\mathrm{CV}_{\mathrm{q}}$ - coeficiente de variação de vazão, \%;

$\mathrm{S}$ - desvio-padrão da vazão dos gotejadores, $\mathrm{L} \mathrm{h}^{-1}$, e

q - vazão média do gotejador, $\mathrm{L} \mathrm{h}^{-1}$.

$$
\mathrm{UD}=\frac{\mathrm{q}_{25 \%}}{\mathrm{q}_{\text {média }}} 100
$$

em que,

UD - uniformidade de distribuição, \%;

$\mathrm{q}_{25 \%}$ - vazão média de $1 / 4$ dos menores valores (três gotejadores), $\mathrm{L} \mathrm{h}^{-1}, \mathrm{e}$

$\mathrm{q}_{\text {média }}$ - vazão média, $\mathrm{L} \mathrm{h}^{-1}$.

$$
\mathrm{GE}=\left(1-\frac{\mathrm{q}_{\text {usado }}}{\mathrm{q}_{\text {novo }}}\right) 100
$$

em que,

GE - grau de entupimento, $\%$.

\section{RESULTADOS E DISCUSSÃO}

Do ponto de vista prático, a vazão média de emissores pode ser considerada bom parâmetro para avaliar alterações quanto ao funcionamento adequado de emissores, seja devido a problemas de entupimento, seja a outros problemas (CARARO et al., 2006; MÉLO, 2007).

Os gotejadores convencionais analisados apresentaram desempenhos diversos, provavelmente em função da arquitetura de cada gotejador. Foram observados valores expressivos de entupimento para alguns, enquanto outros não apresentaram distúrbios expressivos de vazão, com relação à suscetibilidade ao entupimento por aplicação de cloreto de potássio branco e vermelho, combinados com as qualidades de água.

Analisando a Figura 2, é possível visualizar o desempenho de todos os gotejadores para os respectivos tratamentos, fazendo uma classificação geral dos mesmos quanto a sua suscetibilidade ao entupimento em: baixa, média e alta. Assim, os modelos de tubos gotejadores C3, C4 e C7 apresentaram melhor desempenho com valores de entupimento abaixo de $8 \%$ para os diferentes tratamentos, sendo considerados como de baixa suscetibilidade. Os modelos C1 e C2, de modo geral, apresentaram desempenho moderado com valores de entupimento entre $10 \%$ e $18 \%$ para a maioria dos tratamentos, podendo ser classificados como de média suscetibilidade. E os modelos C5, C6 e C8 foram os que tiveram o pior desempenho (maior redução de vazão), apresentando valores de entupimento acima de $20 \%$ e chegando a $77 \%$ de redução de vazão, com exceção dos tratamentos T1-Lg/B e T2-Lg/V do modelo C5, que apresentaram valores abaixo de 7,1\%, sendo, portanto, considerados como de alta suscetibilidade ao entupimento. 


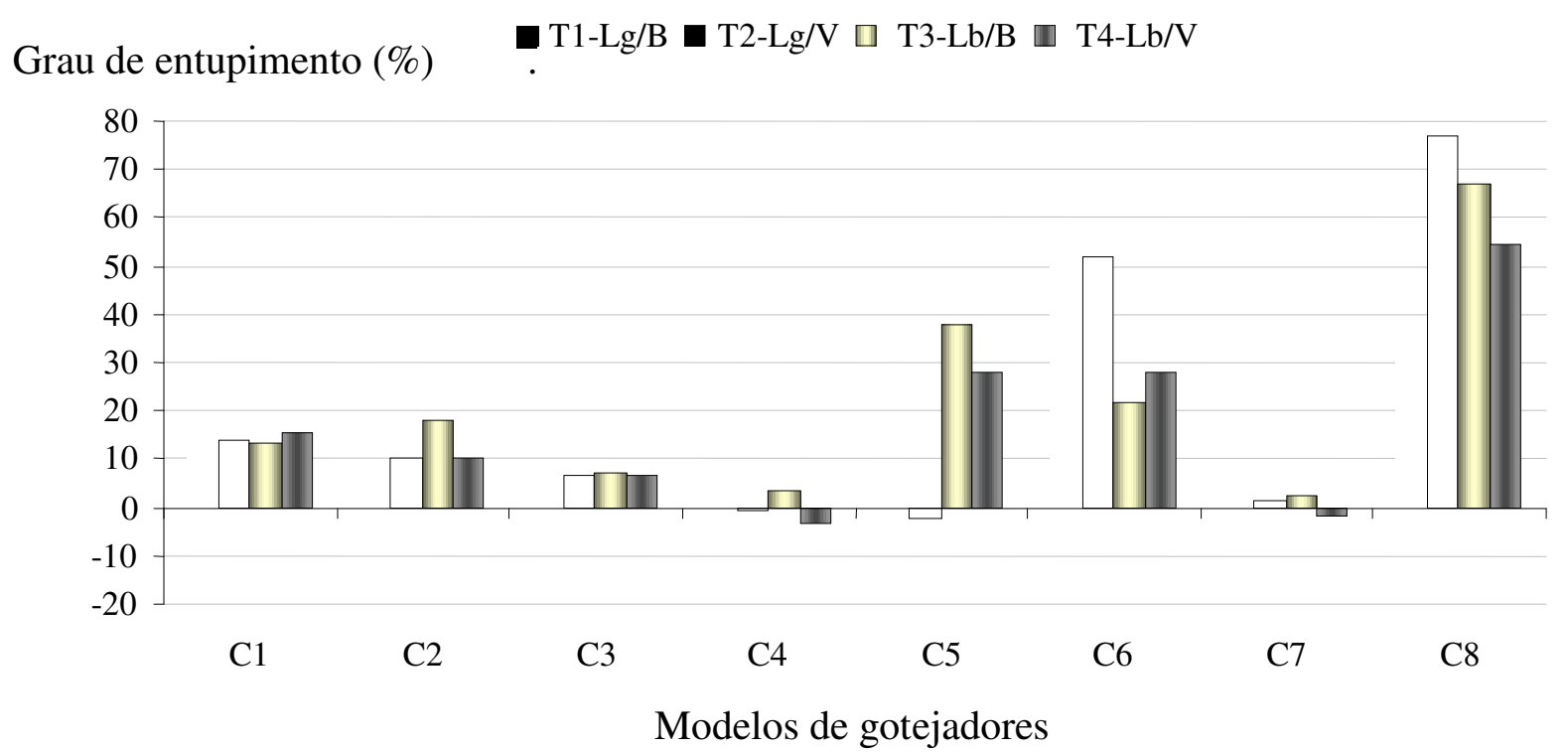

FIGURA 2. Entupimento (\%) dos modelos convencionais de tubos gotejadores nos diferentes tratamentos, após 936 horas de irrigação. Clogging (\%) of conventional dripper models under different treatments after 936 hours of irrigation.

Com relação ao tipo de cloreto de potássio utilizado no ensaio, os valores encontrados não evidenciaram os resultados esperados, em que os tratamentos com aplicação de cloreto de potássio vermelho, teoricamente, apresentariam menor desempenho, com maior porcentagem de entupimento e valores de uniformidade de distribuição inferiores aos dos tratamentos com aplicação de Cloreto de potássio Branco. Neste caso, apenas o modelo C8 apresentou valor mais expressivo de entupimento para o tratamento $\mathrm{T} 2-\mathrm{Lg} / \mathrm{V}$, com $77 \%$ de redução de vazão, comparado ao tratamento $\mathrm{T} 1-\mathrm{Lg} / \mathrm{B}$, com $36,2 \%$ de entupimento. No entanto, para os tratamentos aplicados via água do laboratório, esse mesmo comportamento entre os diferentes tipos de cloreto de potássio não foi observado.

Os modelos C2 e C3 também apresentaram comportamento semelhante ao C8 com relação ao entupimento dos emissores submetidos ao tratamento T2-Lg/V (cloreto de potássio vermelho), com 10 e $6,5 \%$ de entupimento, em comparação a 0,8 e 1,3\% de entupimento para o tratamento T1- $\mathrm{Lg} / \mathrm{B}$ (cloreto de potássio branco).

Com relação à qualidade de água, apenas o modelo C6 apresentou maiores distúrbios de vazão, utilizando-se de água do lago com presença de matéria orgânica (plâncton), comparado aos tratamentos irrigados com água do laboratório. Os resultados foram 59,5 e 52,1\% de entupimento para os tratamentos T1-Lg/B e T2-Lg/ (água do lago), em relação aos tratamentos T3-Lg/B e T4-Lg/ (água do laboratório), com 21,9 e 27,7\% de entupimento.

O modelo C7 apresentou comportamento semelhante aos modelos $\mathrm{C} 3$ e $\mathrm{C} 4$, com 1,2; 1,5; 2,4 e $-1,7 \%$ de entupimento para os tratamentos T1-Lg/B, T2-Lg/V, T3-Lg/B e T4-Lg/V, respectivamente. É importante ressaltar que alguns modelos tiveram redução de vazão e outros apresentaram aumento de vazão. Assim, os valores positivos indicam entupimento com redução de vazão, e valores negativos indicam entupimento com aumento de vazão, concordando com MÉLO (2007).

Na Tabela 2, são apresentados os valores de coeficiente de variação e uniformidade de distribuição dos modelos C3, C4 e C7. 
TABELA 2. Coeficiente de variação (\%) e uniformidade de distribuição (\%) dos tubos gotejadores C3, C4 e C7 após 936 horas de irrigação. Flow rate variation coefficient (\%) and uniformity of distribution (\%) for drippers C3, C4 and C7 after 936 hours of irrigation.

\begin{tabular}{|c|c|c|c|c|c|c|c|c|c|c|}
\hline \multirow{2}{*}{$\begin{array}{c}\text { Tratamentos } \\
\text { Horas } \rightarrow\end{array}$} & \multirow{2}{*}{$\begin{array}{c}\text { L Refer* } \\
0\end{array}$} & \multicolumn{4}{|c|}{ Coeficiente de Variação (\%) } & \multirow{2}{*}{$\begin{array}{c}\text { L Refer } \\
0\end{array}$} & \multicolumn{4}{|c|}{ Uniformidade de Distribuição (\%) } \\
\hline & & 72 & 360 & 648 & 936 & & 72 & 360 & 648 & 936 \\
\hline \multicolumn{11}{|l|}{ Modelo C3 } \\
\hline T1-Lg/B & 1,9 & 3,7 & 1,9 & 4,7 & 2,2 & 97,7 & 97,0 & 97,7 & 94,7 & 97,9 \\
\hline $\mathrm{T} 2-\mathrm{Lg} / \mathrm{V}$ & 3,7 & 1,2 & 3,0 & 6,0 & 3,1 & 95,8 & 98,9 & 96,7 & 94,1 & 97,3 \\
\hline $\mathrm{T} 3-\mathrm{Lb} / \mathrm{B}$ & 1,5 & 3,3 & 2,2 & 2,0 & 2,6 & 98,2 & 96,5 & 97,2 & 97,9 & 97,2 \\
\hline $\mathrm{T} 4-\mathrm{Lb} / \mathrm{V}$ & 3,4 & 2,1 & 2,3 & 2,0 & 3,2 & 96,5 & 97,8 & 97,8 & 97,7 & 96,5 \\
\hline \multicolumn{11}{|l|}{ Modelo C4 } \\
\hline T1-Lg/B & 3,1 & 2,3 & 3,0 & 2,5 & 4,6 & 96,5 & 97,3 & 96,7 & 97,2 & 94,5 \\
\hline T2-Lg/V & 6,2 & 3,1 & 3,3 & 3,7 & 3,8 & 92,4 & 96,6 & 96,5 & 96,3 & 96,6 \\
\hline $\mathrm{T} 3-\mathrm{Lb} / \mathrm{B}$ & 2,2 & 3,6 & 7,6 & 3,3 & 4,1 & 98,7 & 96,2 & 92,3 & 96,5 & 95,2 \\
\hline T4-Lb/V & 3,5 & 2,7 & 3,6 & 3,1 & 3,7 & 95,5 & 96,7 & 95,8 & 96,7 & 95,9 \\
\hline \multicolumn{11}{|l|}{ Modelo C7 } \\
\hline T1-Lg/B & 5,8 & 5,4 & 5,4 & 7,1 & 5,1 & 94,3 & 95,3 & 95,3 & 92,6 & 94,9 \\
\hline $\mathrm{T} 2-\mathrm{Lg} / \mathrm{V}$ & 3,9 & 3,6 & 2,8 & 3,0 & 3,2 & 96,0 & 96,7 & 97,1 & 97,1 & 97,0 \\
\hline T3-Lb/B & 6,7 & 7,0 & 7,3 & 12,6 & 6,4 & 93,8 & 93,1 & 93,3 & 90,4 & 93,6 \\
\hline $\mathrm{T} 4-\mathrm{Lb} / \mathrm{V}$ & 4,0 & 3,5 & 4,0 & 6,2 & 4,2 & 96,3 & 96,6 & 96,0 & 93,1 & 95,3 \\
\hline
\end{tabular}

* L Refer: primeira leitura de vazão (leitura de referência).

O coeficiente de variação de vazão dos modelos de gotejadores, após 72 horas de funcionamento do sistema utilizando água tratada, variou de $1,2 \%$ a 3,7\% para o modelo $\mathrm{C} 3 ; 2,3 \%$ a $3,6 \%$ para o modelo $\mathrm{C} 4$; e $3,5 \%$ a $7,0 \%$ para o modelo $\mathrm{C} 7$, podendo ser classificados como excelentes a médios, segundo a classificação de uniformidade de SOLOMON (1979), em que $\mathrm{CV}_{\mathrm{f}}$ de até 3\% é considerado excelente; de 4 a 7\% médio; de 8 a 10\% marginal; de 11 a 14\% pobre, e acima de $15 \%$ inaceitável.

Após a aplicação dos tratamentos, os modelos de gotejadores C3, C4 e C7 apresentaram valores de coeficiente de variação bem aceitáveis, com valores abaixo de 6,4\% (T3-Lb/B), após $936 \mathrm{~h}$ de uso (Tabela 2). A uniformidade de distribuição de água (\%) desses gotejadores ficou acima de $90 \%$, com destaque para o modelo C3, com 97,9; 97,3; 97,2 e 96,5\% para os tratamentos T1-Lg/B, T2-Lg/V, T3-Lg/B e T4-Lg/V, respectivamente, podendo ser classificado como excelente, segundo SOLOMON (1979).

Na Tabela 3, são apresentados os valores de coeficiente de variação e uniformidade de distribuição dos modelos $\mathrm{C} 1$ e C2.

O coeficiente de variação de vazão, após 936 horas, variou de 3,1 a 10,3\% para o modelo C1 e de 4,9 a $10,4 \%$ para o modelo $\mathrm{C} 2$. Foram observados valores próximos de $7 \%$ para todos os tratamentos, com exceção do $\mathrm{T} 2-\mathrm{Lg} / \mathrm{V}$, para ambos os modelos. $\mathrm{O}$ modelo $\mathrm{C} 1$, utilizando o tratamento $\mathrm{T} 1-\mathrm{Lg} / \mathrm{B}$, foi o que apresentou o menor valor de uniformidade de distribuição $(86,6 \%)$, após $936 \mathrm{~h}$ de ensaio. 
TABELA 3. Coeficiente de variação (\%) e uniformidade de distribuição (\%) dos tubos gotejadores $\mathrm{C} 1$ e $\mathrm{C} 2$ após 936 horas de irrigação, referente à primeira fase. First stage flow rate variation coefficient (\%) and uniformity of distribution (\%) for drippers $\mathrm{C} 1$ and C2 after 936 hours of irrigation, referring to the first stage.

\begin{tabular}{|c|c|c|c|c|c|c|c|c|c|c|}
\hline \multirow{2}{*}{$\begin{array}{c}\text { Tratamentos } \\
\text { Horas } \rightarrow\end{array}$} & \multirow{2}{*}{$\begin{array}{c}\text { L Refer } \\
0\end{array}$} & \multicolumn{4}{|c|}{ Coeficiente de Variação (\%) } & \multirow{2}{*}{$\begin{array}{c}\text { L Refer } \\
0\end{array}$} & \multicolumn{4}{|c|}{ Uniformidade de Distribuição (\%) } \\
\hline & & 72 & 360 & 648 & 936 & & 72 & 360 & 648 & 936 \\
\hline \multicolumn{11}{|c|}{ Modelo C1 } \\
\hline T1-Lg/B & 1,8 & 1,6 & 1,6 & 1,7 & 10,3 & 98,6 & 98,2 & 98,8 & 97,9 & 86,6 \\
\hline T2-Lg/V & 1,5 & 1,0 & 5,9 & 1,7 & 3,1 & 98,2 & 98,8 & 96,9 & 98,4 & 97,0 \\
\hline T3-Lb/B & 2,5 & 1,1 & 2,1 & 3,1 & 6,6 & 97,6 & 98,9 & 97,4 & 96,9 & 94,4 \\
\hline $\mathrm{T} 4-\mathrm{Lb} / \mathrm{V}$ & 5,4 & 0,9 & 1,0 & 4,3 & 7,0 & 96,3 & 98,8 & 98,7 & 95,1 & 92,6 \\
\hline \multicolumn{11}{|l|}{ Modelo C2 } \\
\hline T1-Lg/B & 2,3 & 1,5 & 2,7 & 2,7 & 10,4 & 97,7 & 98,2 & 97,3 & 97,4 & 91,6 \\
\hline T2-Lg/V & 2,5 & 2,8 & 2,2 & 2,6 & 4,9 & 97,0 & 96,8 & 97,7 & 97,4 & 94,2 \\
\hline T3-Lb/B & 2,3 & 4,2 & 2,8 & 4,3 & 6,8 & 98,1 & 95,1 & 97,2 & 94,8 & 92,2 \\
\hline T4-Lb/V & 1,8 & 1,3 & 1,5 & 4,6 & 6,6 & 97,8 & 98,7 & 98,3 & 95,0 & 92,3 \\
\hline
\end{tabular}

* L Refer: primeira leitura de vazão (leitura de referência).

$\mathrm{Na}$ Tabela 4, são apresentados os valores de coeficiente de variação e uniformidade de distribuição dos modelos C5, C6 e C8.

TABELA 4. Coeficiente de variação (\%) e uniformidade de distribuição (\%) dos tubos gotejadores C5, C6 e C8 após 936 horas de irrigação. Flow rate variation coefficient (\%) and uniformity of distribution (\%) for drippers C5, C6 and C8 after 936 hours of irrigation.

\begin{tabular}{|c|c|c|c|c|c|c|c|c|c|c|}
\hline \multirow{2}{*}{$\begin{array}{c}\text { Tratamentos } \\
\text { Horas } \rightarrow\end{array}$} & \multirow{2}{*}{$\begin{array}{c}\text { L Refer } \\
0\end{array}$} & \multicolumn{4}{|c|}{ Coeficiente de Variação (\%) } & \multirow{2}{*}{$\begin{array}{c}\text { L Refer } \\
0\end{array}$} & \multicolumn{4}{|c|}{ Uniformidade de Distribuição (\%) } \\
\hline & & 72 & 360 & 648 & 936 & & 72 & 360 & 648 & 936 \\
\hline \multicolumn{11}{|l|}{ Modelo C5 } \\
\hline T1-Lg/B & 1,0 & 0,8 & 0,8 & 2,6 & 6,4 & 98,9 & 99,2 & 99,2 & 96,6 & 92,2 \\
\hline T2-Lg/V & 1,6 & 5,5 & 0,3 & 1,8 & 2,8 & 98,2 & 96,7 & 99,8 & 98,2 & 97,0 \\
\hline $\mathrm{T} 3-\mathrm{Lb} / \mathrm{B}$ & 2,2 & 1,1 & 4,5 & 14,5 & 37,4 & 97,9 & 98,8 & 94,6 & 83,3 & 55,5 \\
\hline $\mathrm{T} 4-\mathrm{Lb} / \mathrm{V}$ & 1,3 & 1,2 & 2,5 & 3,5 & 12,8 & 98,5 & 98,5 & 97,1 & 95,8 & 88,2 \\
\hline \multicolumn{11}{|l|}{ Modelo C6 } \\
\hline T1-Lg/B & 5,3 & 7,8 & 13,4 & 12,5 & 46,4 & 95,0 & 90,4 & 84,0 & 84,4 & 53,2 \\
\hline T2-Lg/V & 4,5 & 30,6 & 26,4 & 8,1 & 22,8 & 95,4 & 80,7 & 84,0 & 90,4 & 75,1 \\
\hline T3-Lb/B & 3,4 & 3,0 & 2,7 & 8,5 & 12,9 & 95,9 & 96,1 & 97,3 & 90,1 & 83,4 \\
\hline T4-Lb/V & 4,2 & 4,8 & 4,5 & 8,4 & 12,6 & 96,1 & 95,1 & 95,4 & 90,6 & 83,9 \\
\hline \multicolumn{11}{|l|}{ Modelo C8 } \\
\hline T1-Lg/B & 3,4 & 3,6 & 12,6 & 13,9 & 52,4 & 95,9 & 95,3 & 86,5 & 85,6 & 37,0 \\
\hline T2-Lg/V & 16,5 & 12,8 & 56,7 & 74,3 & 126,4 & 89,3 & 92,5 & 34,5 & 12,8 & 11,2 \\
\hline T3-Lb/B & 4,7 & 4,7 & 21,9 & 103,0 & 102,6 & 95,3 & 95,2 & 74,5 & 28,4 & 5,5 \\
\hline T4-Lb/V & 6,4 & 3,9 & 9,3 & 15,9 & 59,6 & 93,1 & 95,2 & 88,8 & 81,7 & 31,0 \\
\hline
\end{tabular}

* L Refer: primeira leitura de vazão (leitura de referência).

Analisando a Tabela 4, observa-se que esses modelos atingiram valores inadequados de coeficiente de variação de vazão e uniformidade de distribuição, após 936 horas de aplicação dos tratamentos. O modelo $\mathrm{C} 8$, com valor mais expressivo de entupimento, atingiu $126,4 \%$ de coeficiente de variação no tratamento T2-Lg/V e uniformidade de distribuição igual a 11,2\%. O modelo C5 apresentou problemas de desuniformidade para o tratamento T3-Lb/B, após 936 horas de irrigação. No entanto, manteve uma boa uniformidade de distribuição para os tratamentos T1Lg/B (92,2\%) e T2-Lg/V (97,0\%), sugerindo melhor adaptação à irrigação com água de menor qualidade, nesses dois casos. 


\section{CONCLUSÕES}

Os modelos de tubos gotejadores apresentaram desempenhos variáveis, tanto na suscetibilidade ao entupimento quanto no coeficiente de variação de vazão, sugerindo que a arquitetura interna dos gotejadores avaliados foi o fator determinante na caracterização do processo de entupimento.

Não foram observados distúrbios de vazão com relação à aplicação dos cloretos de potássio branco e vermelho, na ausência ou presença de fitoplâncton na água de irrigação, mostrando que é possível fazer uso do cloreto de potássio vermelho em fertirrigação. Como existem vários fornecedores de cloreto de potássio vermelho no Brasil, é importante certificar-se da ausência do elemento ferro no adubo (análise de laboratório), para evitar problemas de entupimento em tubos gotejadores devido à fertirrigação com esse produto.

\section{AGRADECIMENTOS}

Ao Ministério da Ciência e Tecnologia (MCT), ao Conselho Nacional de Desenvolvimento Científico e Tecnológico $(\mathrm{CNPq})$ e à Fundação de Amparo à Pesquisa do Estado de São Paulo (FAPESP), pelo apoio financeiro a esta pesquisa, por meio do Instituto Nacional de Ciência e Tecnologia em Engenharia da Irrigação (INCTEI).

\section{REFERÊNCIAS}

AYERS, R.S.; WESTCOT, D.W. A qualidade da água na agricultura. Tradução: R.S. Gheyi, J.F. de Medeiros e F.A.V. Damasceno. Campina Grande: UFPB, 1991. 218 p. (Estudos FAO. Irrigação e Drenagem, 29).

CARARO, D.C.; BOTREL, T.A.; HILLS, D.J.; LEVERENZ, H.L. Analysis of clogging in drip emitters during wastewater irrigation. Applied Engineering in Agriculture, St. Joseph, v.22, n.2, p.251-257, 2006.

COELHO, R.D. Contribuições para a irrigação pressurizada no Brasil. 2007. 192 f. Tese (Livre-Docência) - Escola Superior de Agricultura "Luiz de Queiroz", Universidade de São Paulo, Piracicaba, 2007.

CORDEIRO, E.A.; VIEIRA, G.H.S.; MANTOVANI, E.C. Principais causas de obstruções de gotejadores e possíveis soluções. Revista Engenharia na Agricultura, Viçosa - MG, n.6, p.41, mar. 2003.

MÉLO, R.F. Dinâmica e controle do entupimento de gotejadores em função de precipitados químicos e plâncton. 2007. 189 f. Tese (Doutorado em Irrigação e Drenagem) - Escola Superior de Agricultura "Luiz de Queiroz", Universidade de São Paulo, Piracicaba, 2007.

PIZARRO, F. Riegos localizados de alta frequencia. 3.ed. Madri: Mundi Prensa, 1996. 513 p.

RESENDE, R.S. Suscetibilidade de gotejadores ao entupimento de causa biológica e avaliação do desentupimento via cloração da água de irrigação. 1999. 77 f. Dissertação (Mestrado em Irrigação e Drenagem ) - Escola Superior de Agricultura "Luiz de Queiroz", Universidade de São Paulo, Piracicaba, 1999.

SOLOMON, K.H. Variability of sprinkler coefficient of uniformity test results. Transactions of $A S A E$, St. Joseph, v.22, n.5, p.1.078-1.080, 1.086, 1979.

SOUZA, J.A.A.; CORDEIRO, E.A.; COSTA, E.L. Aplicação de hipoclorito de sódio para recuperação de gotejadores entupidos em irrigação com água ferruginosa. Revista Brasileira de Engenharia Agrícola e Ambiental, Campina Grande, v.10, n.1, p.5-9, 2006. 